\title{
The Coronary Microcirculation in Hamster-to-Rat Cardiac Xenografts
}

\author{
Dominik Geiger ${ }^{a, c}$ Stefan Buchholz ${ }^{a}$ Sebastian Michel ${ }^{a} \quad$ Jan Abicht ${ }^{b, c}$ \\ Christoph A. Reichel ${ }^{c, d}$ Bruno Reichart ${ }^{c}$ Christian Hagl ${ }^{a}$ Paolo Brenner ${ }^{a}$ \\ René Schramma \\ ${ }^{a}$ Clinic of Cardiac Surgery, ${ }^{b}$ Department of Anaesthesiology, ${ }^{c}$ Walter Brendel Centre of \\ Experimental Medicine, d Department of Otorhinolaryngology, Head and Neck Surgery, \\ Ludwig Maximilians University Munich, Munich, Germany
}

\section{Key Words}

Coronary microcirculation - Leukocyte recruitment $\cdot$ Myocardial ischaemia $\cdot$ Reperfusion injury $\cdot$ Xenotransplantation

\begin{abstract}
Background: The aim of this study was to establish a new experimental model to directly analyse the coronary microcirculation in cardiac xenografts. Methods: Intravital fluorescence microscopy (IVM) of the subepicardial microcirculation in heterotopically transplanted hamster-to-rat cardiac xenografts was performed at 30 and $90 \mathrm{~min}$ of reperfusion. We quantitatively assessed the microcirculatory perfusion characteristics as well as the interactions of leukocytes and platelets with the endothelium of postcapillary coronary venules in non-sensitised as well as sensitised recipients. Results: In this first experimental IVM study of cardiac xenografts, we successfully visualised the subepicardial microcirculation, i.e. feeding arterioles, nutritive capillaries and draining postcapillary venules, during reperfusion. Leukocyteendothelial and platelet-endothelial cell interactions could be quantified. In the non-sensitised group, the myocardial microcirculation remained stable during the observation period of $90 \mathrm{~min}$, whereas in the sensitised group, xenografts were rejected immediately. Conclusions: We established a model for the assessment of the microcirculatory dysfunction and inflammation during ischaemia/reperfusion injury in hamster-to-rat cardiac xenografts.
\end{abstract}


Geiger et al.: The Coronary Microcirculation in Hamster-to-Rat Cardiac Xenografts

\section{Introduction}

Xenogeneic transplantation is the transmission of organs, tissues or cells across species. It is thought to be a reasonable option solving the dramatic lack of donor organs in allogeneic transplantation. However, depending on the phylogenetic difference between donors and recipients, mostly immunological hurdles need to be overcome for successful xenogeneic transplantation [1-3].

Xenotransplants undergo hyperacute rejection within minutes due to preformed natural antibodies in the recipient directed against donor antigens, which leads to the activation of complement followed by the destruction of the endothelium [4]. This disintegration of the endothelium causes massive oedema and interstitial haemorrhage [4-6]. Additional activation of the coagulation system enforces a pro-coagulant state with intravascular thrombus formation, subsequent tissue infarction and loss of graft function [7, 8]. So far, these pathophysiological features of hyperacute rejection following xenogeneic transplantation have only been reconstructed indirectly by histological analyses of rejected xenografts $[9,10]$. Direct in vivo analyses of microvascular dysfunction during ischaemia/reperfusion injury and hyperacute rejection after xenogeneic transplantation have not been reported. In particular, intravital analyses of leukocyte- and platelet-endothelial cell interactions in cardiac xenografts have not been performed so far.

In this study, we therefore established and validated an experimental model for direct intravital microscopic analyses of the subepicardial coronary microcirculation in xenogeneically transplanted rodent hearts.

\section{Materials and Methods}

\section{Animals}

Syrian golden hamsters (Charles River, Sulzfeld, Germany) and Lewis rats (Charles River) were used as donors and recipients, respectively. The animals were kept in a 12-hour light and dark cycle and had free access to standard pellet food and tap water. All experiments were performed in accordance with the legislation on the protection of animals and were approved by the Governmental Ethical Committee for Animal Experimentation. For all surgical interventions, anaesthesia was induced by an i.p. injection of $60 \mathrm{mg} / \mathrm{kg}$ body weight of pentobarbital sodium (Merial, Hallbergmoos, Germany). Analgesia was applied by intermittent intramuscular bolus injection of $15 \mathrm{mg} / \mathrm{kg}$ piritramide (Janssen-Cilag, Neuss, Germany). Animals were placed on a heating pad to maintain a body temperature of $37^{\circ} \mathrm{C}$. Animals were sacrificed after experimentation in deep anaesthesia by midline sternotomy and diaphragmatomy.

\section{Heterotopic Cardiac Xenotransplantation}

Heterotopic heart transplantation to the cervical vessels was performed as previously described [11]. Briefly, in Lewis rats (recipients), the right jugular vein and common carotid artery were dissected free through a right paramedian incision at the ventral aspect of the neck. The vein and artery were ligated just below the mandible and bifurcation. Microhaemostats were utilised to clamp the carotid artery and jugular vein at the most proximal sites. Polyethylene cuffs of approximately $2 \mathrm{~mm}$ length and 0.8 and $1.2 \mathrm{~mm}$ in diameter for the arterial and venous cuffs, respectively, were fixed onto both vessels (fig. 1). Systemic heparin treatment was not used. In anaesthetised hamsters (donors), a midline laparotomy was performed. After ligation of the large splanchnic vessels, the intraabdominal aorta was cannulated with a polyethylene catheter (0.8 mm outer diameter) to prepare for subsequent cold organ perfusion. Heparin sulphate (100 units in 500 $\mu \mathrm{l}$ phosphate-buffered saline) was slowly injected into the donors' inferior vena cava. After $2 \mathrm{~min}$, the inferior vena cava was incised, and perfusion of the heart via the aortic cannula with ice-cold Bretschneider HTK solution (100 cm H2 O, Dr. F. Köhler Chemie, Bensheim, Germany) was started immediately. This was followed by incision of the diaphragm. After 10 min of cold perfusion, a midline sternotomy was performed and the ascending aorta was mobilised and transsected at the origin of the brachiocephalic trunk, just prior to the aortic arch. The pulmonary trunk was also mobilised and transsected at the bifurcation. Pulmonary and caval 


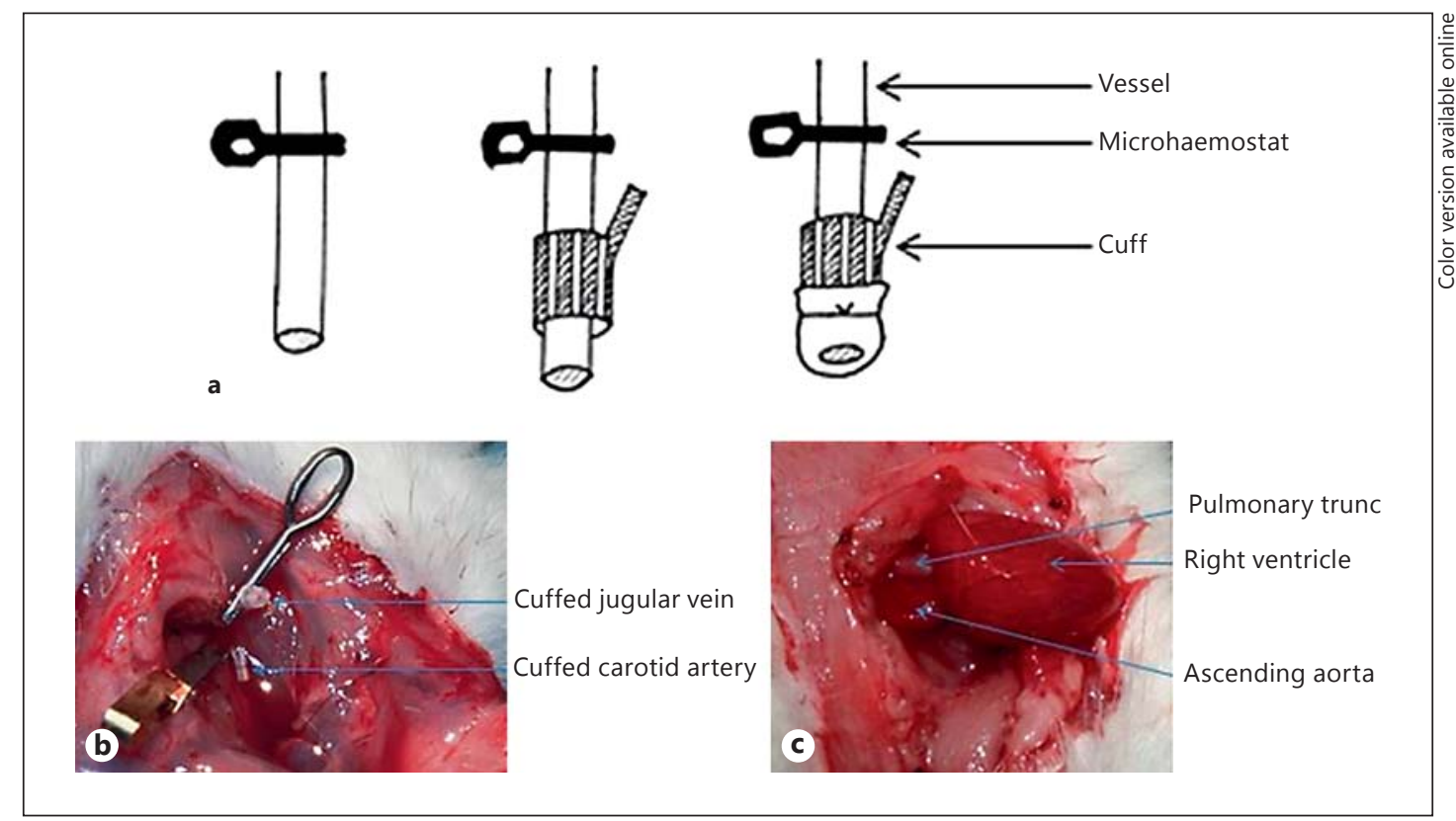

Fig. 1. Microsurgical technique for cuff anastomoses for heterotopic cardiac transplantation. a Schematic depiction of the cuff fixation on a microvessel. b Macroscopic intraoperative view on the situs with the cuffed ends of the right carotid artery and jugular vein. c Macroscopic intraoperative view on the situs after finalising the anastomoses.

veins were collectively ligated by a single mass ligation at the dorsum of the heart and transsected distally. Thus, the donor heart was harvested along with the proximal portions of both great vessels and stored in ice-cold Bretschneider solution until grafting. The arterial and venous cuffed ends of the recipient right carotid artery and jugularvein were introduced and fixed by ligatures into the ascending aortic and pulmonary trunk of the donor graft, respectively. Great care was taken to avoid any manipulation of the epicardial surface during the surgical procedures. Reperfusion of the graft was allowed by removal of the microhaemostats on the recipients' right common carotid artery and jugular vein. All transplantations were performed at 10:00 a.m. by one experienced microsurgeon. The experimental design was approved by the District Government of Upper Bavaria (Application No. 55.2-1-54-2532-29-11).

\section{Intravital Fluorescence Microscopy}

The methodology for intravital fluorescence microscopy (IVM) of the subepicardial microcirculation in heterotopically transplanted mouse hearts has been described in detail previously [12]. Contrast enhancement with sodium fluorescein (molecular weight 376 Da, 0.1 mg i.v., Sigma Chemical Co., St. Louis, Mo., USA) and green-light epi-illumination (450-490 $\mathrm{nm}$ excitation wave length, >520 $\mathrm{nm}$ emission wave length) were used to determine microvascular diameters (in $\mu \mathrm{m}$ ), red blood cell flow velocities (in $\mathrm{mm} / \mathrm{s}$ ) and volumetric blood flow (in pl/s). Leukocyte- and platelet-endothelial cell-adhesive interactions were visualised after i.v. application of rhodamine 6G (molecular weight $479 \mathrm{Da}, 2 \mathrm{mg}$ i.v., Sigma Chemical Co.) and by use of blue-light epi-illumination (530-560 nm excitation wave length, >580 nm emission wave length). Rolling leukocytes and platelets were defined as fluorescent cells rolling along the endothelial microvascular surface in postcapillary venules. For quantification, numbers of rolling leukocytes and platelets were counted within a defined postcapillary venular segment during $30 \mathrm{~s}$ and were expressed as cells $/ \mathrm{min} / \mathrm{mm}^{2}$ endothelial surface. Firm adhesion of leukocytes and platelets was determined by counting the number of fluorescently labelled cells remaining firmly attached to the endothelial surface within a venular segment for at least $30 \mathrm{~s}$ and was expressed as cells $/ \mathrm{mm}^{2}$ endothelial surface. Leukocytes (approx. 8-10 $\mu \mathrm{m}$ ) and platelets (approx. $2 \mu \mathrm{m}$ ) were differentiated by size properties. All microcirculatory parameters were measured in 3 different areas of the right ventricular subepicardial coronary microcirculation per graft at 30 and 90 min of reperfusion. 


\begin{tabular}{l|l}
\hline Eur Surg Res 2015;55:364-373 \\
\hline DOI: 10.1159/000440719 & $\begin{array}{l}\text { @ 2015 S. Karger AG, Basel } \\
\text { www.karger.com/esr }\end{array}$ \\
\hline
\end{tabular}

Geiger et al.: The Coronary Microcirculation in Hamster-to-Rat Cardiac Xenografts

Histology

After experimentation, native recipient Lewis rat hearts and transplanted hamster xenografts were harvested and fixed in $4 \%$ formaldehyde prior to paraffin embedding. Routine hematoxylin-eosin (HE) staining was performed on 3-5 non-sequential central sections of each native rat heart and transplanted xenograft. Experimental hamster-to-rat xenograft rejection was analysed by two independent investigators blinded to the experimental protocol grading the histological alterations of monomorphonuclear cell infiltrates, haemorrhage, the numbers of completely obliterated vessels and loss of cell integrity into $0=$ none, $1=$ mild, 2 = moderate or $3=$ severe. Native recipient hearts were analysed accordingly.

\section{Blood Samples}

Approximately $2 \mathrm{ml}$ of blood were drawn from the caudal vena cava in all transplanted recipients after explantation as well as in naive control rats for serum analyses, blood cell counts and coagulation parameters.

\section{Recipient Sensitisation}

In a separate group, rat recipients received an i.v. injection of $1 \mathrm{ml}$ hamster whole blood 7-10 days prior to the xenogeneic heart transplantation in order to allow the formation of donor-specific antibodies to mimic a completely discordant setting [13].

\section{Experimental Groups}

For IVM analyses, 12 transplantations were performed ( $\mathrm{n}=12$; group 1). Separate transplantations ( $n$ = 5; group 2) were performed without IVM, and the recipients' neck skin was closed immediately after onset of reperfusion. In this semi-discordant setting, animals were allowed to recover from surgery, and graft survival was monitored twice a day by inspection and palpation of the graft under the covering neck skin. Rejection was defined as complete cessation of palpable graft contractions and fibrillations. Recipient sensitisation and subsequent transplantation ( $n=5$; group 3 ) was performed in order to monitor xenogeneic graft survival in a completely discordant transplant setting. Transplanted hamster xenografts and recipient rat native hearts were harvested and histologically analysed after IVM in group 1 as well as after complete rejection in groups 2 and 3. Blood samples were drawn prior to organ harvest in all groups and in an additional set of naive rats for control ( $n=8$; group 4).

\section{Statistics}

Data are given as mean values \pm standard error of the mean (SEM) and $n$ indicates the analysed sample size per group. Statistical differences were calculated using the Mann-Whitney rank-sum test and appropriate post hoc testing for multiple comparisons (SigmaStat Software, Jandel Scientific, USA). Differences were considered significant at $\mathrm{p}<0.05$.

\section{Results}

\section{Heterotopic Cardiac Transplantation}

Heterotopic cardiac transplantation was successfully performed in approximately $90 \%$ of cases showing macroscopically spontaneous injection of blood flow into the coronary vessels immediately after removal of the haemostats from the recipients' common carotid artery and jugular vein. Two experiments were excluded from the study due to acute bleeding complications, and in 2 cases, IVM images could not be obtained due to respiratory failure and death after the 30-min IVM analysis.

\section{Xenograft Survival}

Heterotopically transplanted hamster hearts (group 2) were viable for $3.2 \pm 0.2$ days in naive rat recipients. In sharp contrast, hamster hearts transplanted under completely discordant conditions, namely into sensitised recipients, were hardly functional at all. Rather, upon reperfusion, they were swelling immediately, changed colour to dark purple and lost any detectable contractions or fibrillations within $14.8 \pm 2.8 \mathrm{~s}$ upon declamping. 

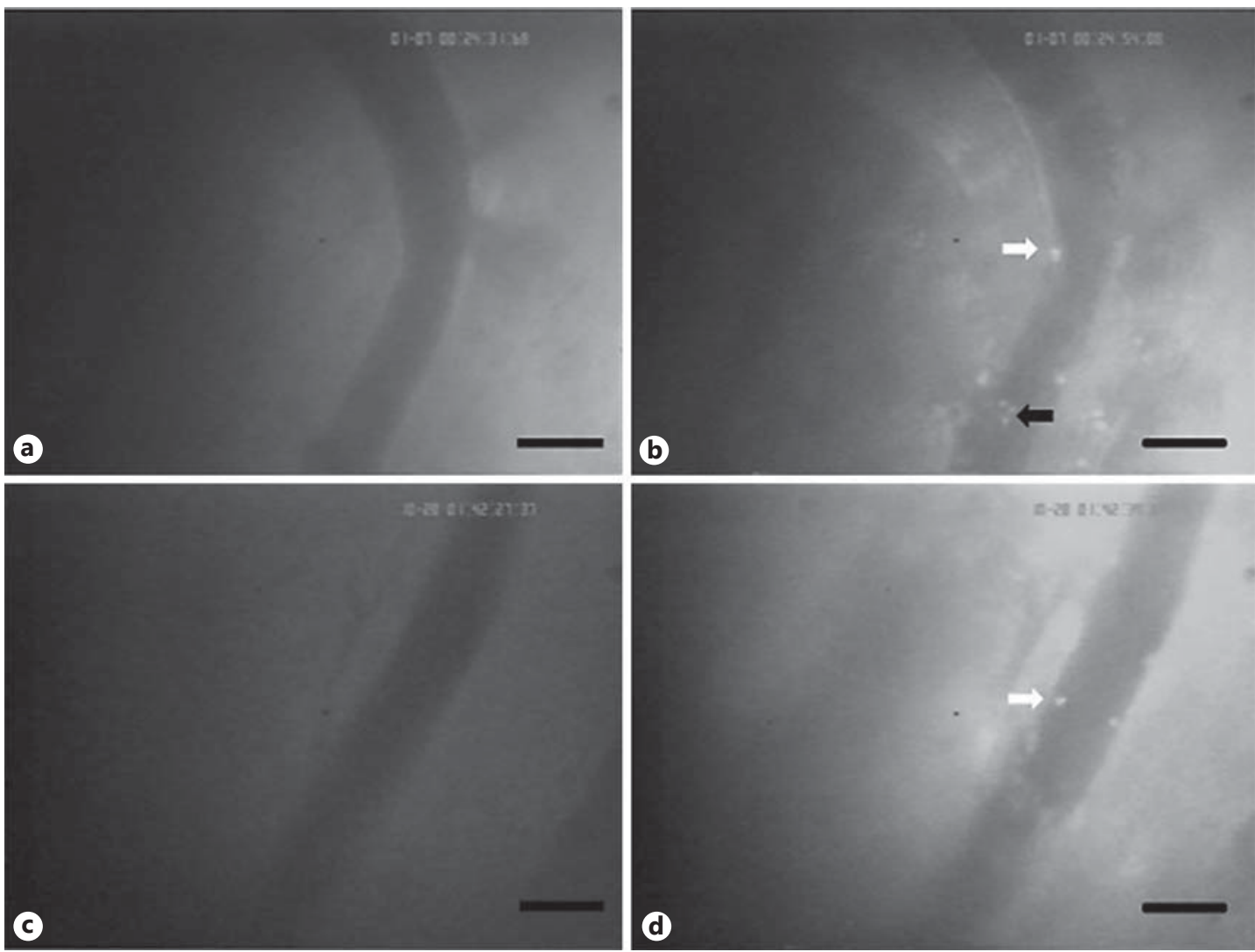

Fig. 2. Representative IVM of the subepicardial microcirculation. IVM images of two subepicardial postcapillary draining venules at $30 \mathrm{~min}(\mathbf{a}, \mathbf{b})$ and $90 \mathrm{~min}(\mathbf{c}, \mathbf{d})$. Contrast enhancement was achieved with fluorescein sodium under green-light epi-illuminescence $(560 \mathrm{~nm} ; \mathbf{a}, \mathbf{c})$ and with rhodamine $6 \mathrm{G}$ under blue-light epi-illuminescence $(510 \mathrm{~nm}$; b, d). Interacting leukocytes (white arrow) and platelets (black arrow) were distinguished by size properties. Scale bar $=60 \mu \mathrm{m}$.

\section{Intravital Fluorescence Microscopy}

Due to the fulminant rejection in the completely discordant setting (group 3), IVM could only be performed in hamster hearts transplanted into naive rat recipients (group 1). IVM allowed a detailed visualisation of the right ventricular subepicardial coronary microcirculation, including feeding arterioles, nutritive capillaries and draining postcapillary venules (fig. 2). Arterioles were inconstantly found solely close to the atrioventricular transition, were penetrating into the deeper myocardial layers thereafter and were not accessible for standardised IVM analysis. Leukocytes could be thoroughly differentiated from platelets because of their markedly bigger size (fig. 2). The off-line-determined quantitative IVM data are shown in table 1.

Analyses of microhaemodynamics showed an increase in both red blood cell flow velocities and volumetric blood flows between 30 and 90 min of reperfusion. However, only the difference in red blood cell flow velocities was statistically significant.

Postischaemic inflammation, as indicated by leukocyte-endothelial cell-adhesive interactions, i.e. rolling and firm adhesion, in the coronary postcapillary venules increased during reperfusion (table 1). In contrast to the leukocyte behaviour, platelet-endothelial celladhesive interactions (both rolling and firm adhesion) decreased during reperfusion. The differences in leukocyte- and platelet-endothelial cell-adhesive interactions between 30 and 
Table 1. Intravital fluorescence microscopy

\begin{tabular}{lccc}
\hline & $30 \min (\mathrm{n}=12)$ & $90 \min (\mathrm{n}=10)$ & $\mathrm{p}$ \\
\hline Red blood cell flow velocity, mm/s & $0.41 \pm 0.01$ & $0.46 \pm 0.01^{\#}$ & $<0.05$ \\
Volumetric blood flow, $\mathrm{pl} / \mathrm{min}$ & $613.40 \pm 83.20$ & $966.04 \pm 158.55$ & 0.052 \\
Leukocyte rolling, cells/min/mm & $92.40 \pm 21.10$ & $140.73 \pm 56.33$ & 0.869 \\
Leukocyte rolling velocity, $\mathrm{mm} / \mathrm{s}$ & $0.02 \pm 0.01$ & $0.03 \pm 0.01$ & 0.552 \\
Leukocyte firm adhesion, cells/mm $\mathrm{mm}^{2}$ & $68.82 \pm 12.97$ & $90.87 \pm 27.68$ & 0.454 \\
Thrombocyte rolling, cells/min/mm $\mathrm{mm}^{2}$ & $294.00 \pm 97.14$ & $110.39 \pm 49.67$ & 0.248 \\
Thrombocyte rolling velocity, $\mathrm{mm} / \mathrm{s}$ & $0.03 \pm 0.01$ & $0.04 \pm 0.02$ & 0.316 \\
Thrombocyte firm adhesion, cells/mm & $233.68 \pm 38.52$ & $194.43 \pm 41.21$ & 0.448 \\
\hline
\end{tabular}

IVM of the right ventricular subepicardial coronary microcirculation was performed in hamster xenografts transplanted into naive, non-sensitised rat recipients (group 1) at 30 and 90 min of reperfusion. Red blood cell flow velocity, volumetric blood flow as well as leukocytic and thrombocytic endothelial cell interactions were determined off line from IVM images with a computer-assisted image analysis software. Data are mean values \pm SEM and $\mathrm{n}$ represents the number of analysed experiments at each time point. ${ }^{\#} \mathrm{p}<0.05$ vs. 30 min.

90 min of reperfusion were not statistically significant. Both leukocyte and platelet rolling velocities increased slightly but not statistically significantly during IVM observations.

\section{Blood Analyses}

Results of blood analyses of all transplanted animals showed increased levels of creatinine kinase, troponin and myoglobin compared to the untreated control group, i.e. naive control rats not subjected to cardiac transplantation. There was no statistically significant difference between the transplanted animals in groups 1-3 (table 2).

\section{Histological Analyses}

Histopathological findings were weak in hamster xenografts harvested immediately after IVM and after hyperacute rejection in sensitised rat recipients, i.e. groups 1 and 3 (table 3). In contrast, rejected hamster xenografts harvested from naive, non-sensitised recipients showed marked loss of cellular integrity, monomorphonuclear cell infiltrations and haemorrhage (fig. 3). Thrombotic microvascular occlusions were rarely found in any group. As expected, native control rat heart specimens were virtually devoid of any histopathological alterations (table 3).

\section{Discussion}

The shortage of donor organs for allogeneic heart transplantation leads to prolonged waiting times and is associated with a high mortality rate for patients on the waiting list [1]. As xenogeneic transplantation could potentially solve the organ shortage in cardiac transplantation, special interest lies in overcoming the mechanisms of xenograft rejection [2, 3]. Several innovations, like genetically modified donor animals [14], achieved increased longterm survival in preclinical xenotransplantation models [15-17]. Yet, cardiac xenotransplantation is still far from being established clinically [18].

It is known that microvascular changes during the early reperfusion of the xenogeneic transplanted cardiac grafts lead to hyperacute rejection. This is characterised by endothelial damage causing interstitial haemorrhage and oedema formation as well as coagulation disorders leading to intravascular thrombosis and consecutive infarction [8]. To date, however, no intravital visualisation of hyperacutely rejected cardiac xenografts has been 
Table 2. Blood results

\begin{tabular}{lcccc}
\hline & Group 1 & Group 2 & Group 3 & Control \\
\hline $\mathrm{n}$ & 6 & 5 & 4 & 7 \\
CK, U/l & $7,528.4 \pm 2,468.7^{\#}$ & $1,968.6 \pm 1,207.9$ & $17,252.40 \pm 10,114.1^{\#}$ & $428.2 \pm 97.7$ \\
Trop. I, ng/ml & $15.99 \pm 9.97^{\#}$ & $20.61 \pm 11.65^{\#}$ & $17.37 \pm 15.00^{\#}$ & $<0.05$ \\
Myo., ng/ml & $7.5 \pm 0.3^{\#}$ & $3.0 \pm 0.0^{\#}$ & $2.5 \pm 0.5^{\#}$ & $4.6 \pm 0.3$ \\
\hline $\mathrm{n}$ & 5 & 5 & 3 & 8 \\
Leu., g/l & $3.56 \pm 1.10$ & $8.68 \pm 1.39^{\#}$ & $3.70 \pm 0.06^{\#}$ & $5.85 \pm 0.66$ \\
Ery., 10 ${ }^{3} / \mathrm{l}$ & $9.62 \pm 0.29^{\#}$ & $7.06 \pm 0.24^{\#}$ & $8.39 \pm 0.29$ & $8.43 \pm 0.31$ \\
Hb, g/dl & $16.56 \pm 0.51^{\#}$ & $11.84 \pm 0.31^{\#}$ & $14.67 \pm 0.53$ & $14.15 \pm 0.37$ \\
Throm., g/l & $523.4 \pm 39.2$ & $497.6 \pm 82.9$ & $586.7 \pm 58.0$ & $559.8 \pm 18.3$ \\
\hline $\mathrm{n}$ & 6 & 5 & 4 & 6 \\
Quick, \% & $126.7 \pm 2.1$ & $151.0 \pm 2.5^{\#}$ & $131.7 \pm 4.4$ & $123.3 \pm 4.7$ \\
INR & $0.85 \pm 0.02$ & $<0.8$ & $0.83 \pm 0.03$ & $0.87 \pm 0.03$ \\
aPTT, s & $<20$ & $<18$ & $<18$ & $<18$ \\
Fibr., mg/dl & $93.0 \pm 20.6$ & $509.0 \pm 37.1^{\#}$ & $135.7 \pm 39.2$ & $121.5 \pm 21.1$ \\
AT, \% & $96.5 \pm 2.7^{\#}$ & $128.6 \pm 6.4^{\#}$ & $91.8 \pm 7.2^{\#}$ & $107.0 \pm 2.0$ \\
\hline
\end{tabular}

Blood results of hamster-to-rat cardiac xenotransplantation in group 1 after 90 min IVM, in group 2 after long-term survival and in group 3 after sensitisation. Different sample numbers are caused by problems in laboratory analyses. Data are mean values \pm SEM and $n$ represents the number of analysed experiments at each time point. $\mathrm{CK}=$ Creatinine kinase; Trop. = troponin; Myo. = myoglobin; Leu. = leukocytes; Ery. = erythrocytes; $\mathrm{Hb}=$ haemoglobin; Throm. = thrombocytes; INR = international normalized ratio; aPTT = activated partial thromboplastin time; Fibr. = fibrinogen; AT = antithrombin. ${ }^{\#}$ p $<0.05$ vs. control.

Table 3. Histological analysis

\begin{tabular}{lllll}
\hline & Group 1 & Group 2 & Group 3 & Control \\
\hline Monomorphonuclear cell infiltrates & $0.2 \pm 0.1$ & $1.8 \pm 0.2^{\#}$ & $0.7 \pm 0.1^{\#}$ & $0.1 \pm 0.1$ \\
Haemorrhage & $0.6 \pm 0.2^{\#}$ & $3.0 \pm 0.0^{\#}$ & $1.2 \pm 0.3^{\#}$ & $0.1 \pm 0.0$ \\
Completely obliterated vessels & $0.0 \pm 0.0$ & $3.0 \pm 0.0^{\#}$ & $0.4 \pm 0.3$ & $0.0 \pm 0.0$ \\
Loss of cell integrity & $1.2 \pm 0.3^{\#}$ & $3.0 \pm 0.0^{\#}$ & $1.7 \pm 0.1^{\#}$ & $0.2 \pm 0.1$ \\
\hline
\end{tabular}

Histological analysis of the transplanted hamster xenografts after IVM (group 1), after long-term survival (group 2) and after sensitisation (group 3). Control indicates the histological score of the native recipient rat hearts. Score system: $0=$ none; $1=$ mild; $2=$ moderate; $3=$ severe. Data are mean values \pm SEM and $n$ represents the number of analysed experiments at each time point. ${ }^{*} p<0.05$ vs. control.

reported. In contrast, the pathophysiological mechanisms of xenogeneic hyperacute rejection have been extrapolated only indirectly from histopathological studies at most. For the first time, we herein used IVM to visualise microcirculatory dysfunction and inflammation directly in the subepicardial microvasculature of transplanted cardiac xenografts. The principle technique has already been proven to be a very valid approach to monitor ischaemia/reperfusion injury and rejection in allogeneic experimental transplantation $[12,19,20]$.

The experimental transplantation setting we used herein is an established heterotopic cervical cardiac transplantation model using a cuff technique in rodents $[11,12]$. This offers an easily applicable transplantation model with excellent access to the transplanted graft for IVM $[12,19,21]$. 

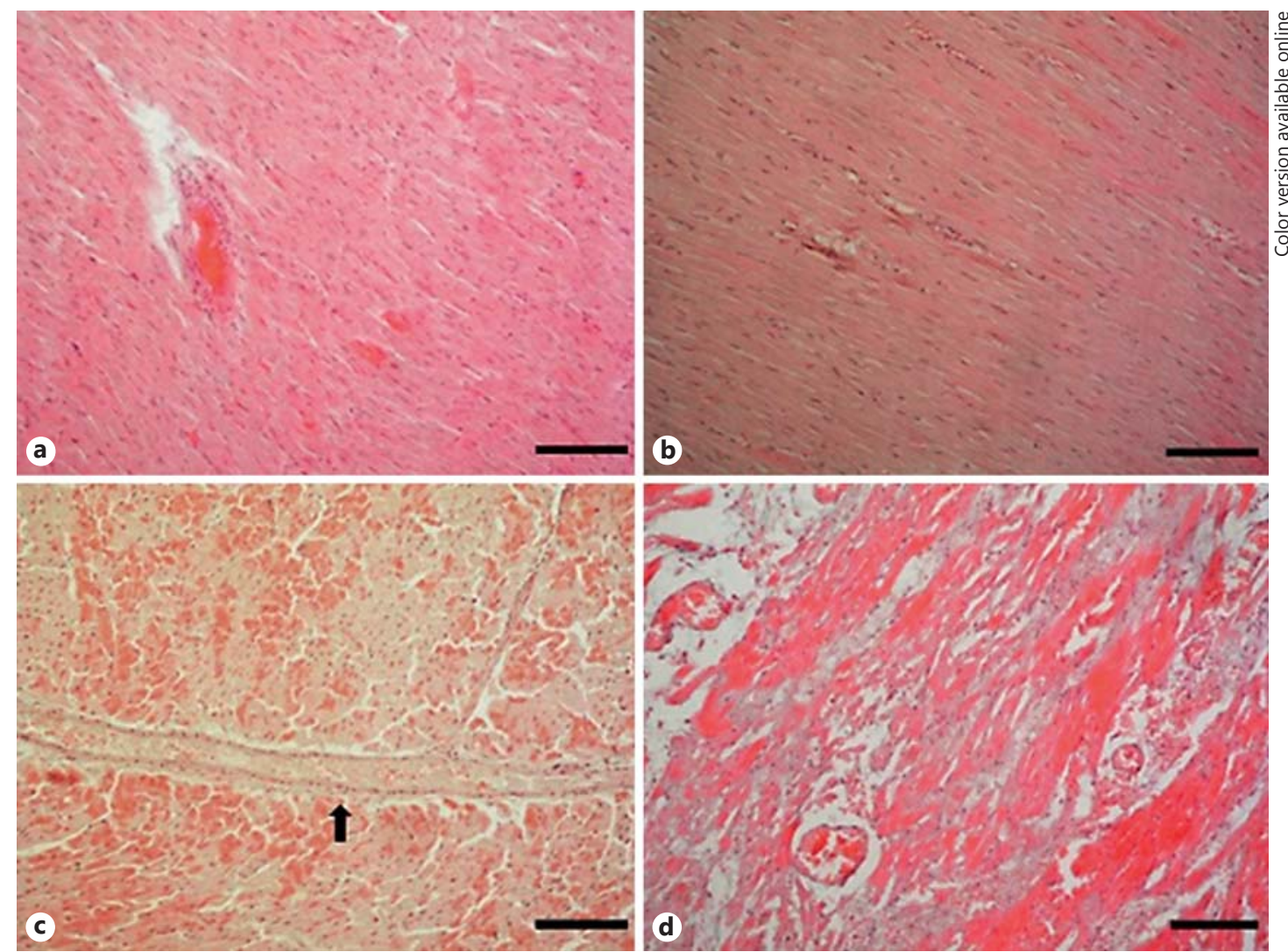

Fig. 3. Representative histological images after hamster-to-rat cardiac xenotransplantation. a Native rat heart (control) showing no histological features of rejection. b Transplanted hamster cardiac xenograft after IVM and 90 min of reperfusion. c Transplanted hamster cardiac xenograft showing arteriolar thrombosis (black arrow). $\mathbf{d}$ Transplanted hamster cardiac xenograft after 3 days indicating marked interstitial haemorrhage and cellular necrosis. HE. Scale bar $=200 \mu \mathrm{m}$.

The strain combination of Syrian golden hamsters as donors and Lewis rats as recipients offers an acknowledged semi-discordant xenotransplantation setting [13]. To achieve a completely discordant transplantation setting, we performed a pre-sensitisation by injection of donor whole blood to the recipients 10 days prior to transplantation, as this protocol has been effectively described previously [13]. Thus, anti-hamster antibody production in the rat recipients is induced. Our data show that this protocol provokes highly effective hyperacute rejection of cardiac xenografts. In fact, xenograft survival in sensitised rat recipients is only marginal with complete rejection occurring within seconds of the beginning of reperfusion. Further, our data indicate the lack of preformed anti-donor antibodies in naive rat recipients, as survival times of semi-discordant cardiac xenografts in non-sensitised rat recipients were significantly higher with complete rejection within days after transplantation. These data are comparable to results reported by others [22-24]. Nevertheless, transplantation of hamster hearts to non-sensitised rat recipients in the semi-discordant setting is in fact a relevant model for xenotransplantation studies, as the survival times are significantly lower when compared to allogeneic rat-to-rat transplantation, which are reported to be around 20 days, depending on the strain combination $[25,26]$.

In view of these observations and due to the rapid destruction of cardiac xenograft function in sensitised rat recipients, intravital microscopic assessment of microvascular 
dysfunction and inflammation could not be performed in this group. The rapid cessation of perfusion did simply not allow to dynamically follow the microvascular mechanisms of hyperacute rejection in these animals. As such, IVM images and data could only be obtained in the semi-discordant setting of cardiac xenotransplantation.

The dynamics of postischaemic microvascular perfusion characteristics, i.e. red blood cell flow velocities and volumetric blood flows, indicate reactive hyperaemia during early reperfusion of cardiac xenografts. The detection of reactive hyperaemia validates our experimental protocol for future IVM assessments of the xenografts' microcirculation addressing dynamic vasoreactivity changes during later reperfusion phases. In fact, prolonged reperfusion injury and the no-reflow phenomenon may hamper later adequate graft perfusion, as it has been observed in experimental cardiac allografts [19].

In this study, IVM also revealed an increased interaction of leukocytes with the endothelium indicating postischaemic inflammation. Both rolling and sticking increased after 90 min of reperfusion when compared with 30 min after reperfusion. In contrast, platelet-endothelial interactions were reduced during the observation period, leading to less sticking and rolling in postcapillary venules after $90 \mathrm{~min}$ of reperfusion. The reasons for these findings remain elusive. The finding of platelet-endothelial cell interactions in postcapillary coronary venules suggests a novel mechanistic aspect in xenogeneic graft destruction, as it has been widely accepted that thromboembolic occlusion of the arteriolar bloodstream leads to infarction and tissue destruction. This is obviously different to allogeneic cardiac rejection, during which such platelet interactions were not observed [19].

Analyses of peripheral blood probes showed increased myocardial markers in all transplanted animals. However, increased troponin levels in the IVM group are most likely caused by cardioplegic arrest and ischaemia/reperfusion injury, whereas increased troponin levels after long-term survival might rather be due to acute rejection and associated myocardial cell injury. The increased myocardial enzyme levels after hyperacute rejection in pre-sensitised recipients appeared too quickly to be explained by ischaemia/reperfusion injury alone. We concluded that this is an expression of massive donor-specific antibody-mediated myocardial cell injury.

Increased circulating leukocyte levels in the survival group may reflect ongoing acute cellular rejection of the xenograft. Increased fibrinogen and antithrombin III levels underline the inflammatory process during rejection.

Histological examination of the transplanted cardiac xenografts demonstrated only weak alterations after 90 min of reperfusion with or without pre-sensitisation. Only the xenografts which were functional for 3 days showed marked histological alterations. Surprisingly, intravascular thrombus formation was rarely seen in all groups. In particular, we did not find intravascular thrombi in the pre-sensitised transplantation group, where xenografts seemed to be hyperacutely rejected within seconds. These data indicate that the myocardial damage during hyperacute cardiac xenograft rejection is rather functional and cannot be detected in histopathological tissue structures at early time points.

Taken together, the experimental approach described in this study is a valid model for direct analyses of microvascular dysfunction, rejection and inflammation in cardiac xenotransplants. Future studies will aim to elucidate the cellular and molecular mechanisms of xenograft rejection in more detail, e.g. by targeting adhesion molecules.

\section{Disclosure Statement}

The authors declare that they have no conflicts of interest to disclose. 


\section{References}

1 Reichart B, Guethoff S, Mayr T, Thormann M, Buchholz S, Postrach J, Ayares D, Elliott RB, Tan P, Kind A, Hagl C, Brenner P, Abicht JM: Discordant cardiac xenotransplantation: broadening the horizons. Eur J Cardiothorac Surg 2014;45:1-5.

2 Cooper DK, Keogh AM, Brink J, Corris PA, Klepetko W, Pierson RN, et al: Report of the Xenotransplantation Advisory Committee of the International Society for Heart and Lung Transplantation: the present status of xenotransplantation and its potential role in the treatment of end-stage cardiac and pulmonary diseases. J Heart Lung Transplant 2000;19:1125-1165.

3 Pierson RN 3rd, Dorling A, Ayares D, Rees MA, Seebach JD, Fishman JA, Hering BJ, Cooper DK: Current status of xenotransplantation and prospects for clinical application. Xenotransplantation 2009;16:263-280.

4 Platt JL, Saadi S: The role of complement in transplantation. Mol Immunol 1999;36:965-971.

5 Bach FH, Robson SC, Ferran C, Winkler H, Millan MT, Stuhlmeier KM, Vanhove B, Blakely ML, van der Werf WJ, Hofer E, De Martin R, Hancok WW: Endothelial cell activation and thromboregulation during xenograft rejection. Immunol Rev 1994;141:5-30.

6 Pierson RN 3rd: Antibody-mediated xenograft injury: mechanisms and protective strategies. Transpl Immunol 2009;21:65-69.

7 Platt JL: The immunological hurdles to cardiac xenotransplantation. J Card Surg 2001;16:439-447.

8 Bustos M, Platt JL: The pathology of cardiac xenografts. J Card Surg 2001;16:357-362.

9 Goddard MJ, Dunning J, Horsley J, Atkinson C, Pino-Chavez G, Wallwork J: Histopathology of cardiac xenograft rejection in the pig-to-baboon model. J Heart Lung Transplant 2002;21:474-484.

10 Tazelaar HD, Byrne GW, McGregor CG: Comparison of Gal and non-Gal-mediated cardiac xenograft rejection. Transplantation 2011;91:968-975.

11 Matsuura A, Abe T, Yasuura K: Simplified mouse cervical heart transplantation using a cuff technique. Transplantation 1991;51:896-898.

12 Schramm R, Menger MD, Kirsch S, Langer F, Harder Y, Hamacher J, Schäfers HJ: The subepicardial microcirculation in heterotopically transplanted mouse hearts: an intravital multifluorescence microscopy study. J Thorac Cardiovasc Surg 2007;134:210-217.

13 Marino IR, Celli S, Catena M, Gatti S, Zetti G, Ferla G, Doyle HR, Maggiano N, Musiani P: Xenotransplantation rejection is antibody-mediated in both sensitized and nonsensitized recipients. J Invest Surg 1994;7:111-122.

14 Phelps CJ, Koike C, Vaught TD, Boone J, Wells KD, Chen SH, Ball S, Specht SM, Polejaeva IA, Monahan JA, Jobst PM, Sharma SB, Lamborn AE, Garst AS, Moore M, Demetris AJ, Rudert WA, Bottino R, Bertera S, Trucco M, Starzl TE, Dai Y, Ayares DL: Production of alpha 1,3-galactosyltransferase-deficient pigs. Science 2003;299:411-414.

15 Mohiuddin MM, Corcoran PC, Singh AK, Azimzadeh A, Hoyt RF Jr, Thomas ML, Eckhaus MA, Seavey C, Ayares D, Pierson RN 3rd, Horvath KA: B-cell depletion extends the survival of GTKO.hCD46Tg pig heart xenografts in baboons for up to 8 months. Am J Transplant 2012;12:763-771.

16 Bauer A, Postrach J, Thormann M, Blanck S, Faber C, Wintersperger B, Michel S, Abicht JM, Christ F, Schmitz C, Schmoeckel M, Reichart B, Brenner P: First experience with heterotopic thoracic pig-to-baboon cardiac xenotransplantation. Xenotransplantation 2010;17:243-249.

17 Byrne GW, McGregor CG: Cardiac xenotransplantation: progress and challenges. Curr Opin Organ Transplant 2012;17:148-154.

18 Ekser B, Ezzelarab M, Hara H, van der Windt DJ, Wijkstrom M, Bottino R, Trucco M, Cooper DK: Clinical xenotransplantation: the next medical revolution? Lancet 2012;379:672-683.

19 Schramm R, Kirsch S, Schäfers HJ, Langer F, Scheuer C, Nickels R, Harder Y, Menger MD: Erythropoietin inhibits post-ischemic leukocyte adhesion but does not affect rejection in murine cardiac allografts. J Heart Lung Transplant 2010;29:1185-1192.

20 Schramm R, Appel F, Reinacher M, Schäfers HJ, Bierbach B, Slotta J, Thorlacius H, Menger MD: Atherosclerosis aggravates ischemia/reperfusion injury in the gut and remote damage in the liver and the lung. Inflamm Res 2011;60:555-567.

21 Schramm R, Schmits R, Schäfers HJ, Menger MD: Simvastatin does not prevent acute cardiac allograft rejection in CD28-deficient mice. Inflamm Res 2009;58:765-771.

22 Wang B, Yi L, Li H, Pan CE: A new cardiac concordant xenotransplantation model. Transplant Proc 2005; 37: 4620-4622.

23 Ginestà MM, Ribas Y, Mollevi DG, Vidal A, Mañez R, Figueras J, Jaurrieta E: Acute xenograft rejection, late xenograft rejection and long term survival xenografts in the hamster-to-rat heart transplantation model: histological characterisation under low-dose of FK506. APMIS 2002;110:737-745.

24 Vriens PW, Stoot JH, van der Steenhoven TJ, Hoyt G, Bouwman E, Robbins RC: Pre-transplant blood transfusion and cyclosporin A induce long-term hamster cardiac xenograft survival in immunocompetent rats. Xenotransplantation 2005;12:63-71.

25 Deuse T, Schrepfer S, Reichenspurner H: The interaction between FK778 and tacrolimus in the prevention of rat cardiac allograft rejection is dose dependent. Transplantation 2004;77:509-513.

26 Fang YH, Joo DJ, Lim BJ, Huh KH, Kim MS, Suh H, Kim YS: The effects of AEB071 (sotrastaurin) with tacrolimus on rat heterotopic cardiac allograft rejection and survival. J Surg Res 2011;171:e133-e137. 